\title{
Cervical Tuberculous Lymphadenitis in a Frequent Traveler to Endemic Areas of Tuberculosis
}

\author{
Yukiharu HAYASE and Kiyotake ToBITA
}

\begin{abstract}
Scrofula or cervical tuberculous lymphadenitis (CTBL) should be suspected in patients with a history of potential exposure to tuberculosis present with cervical lymphadenopathy. A 55 yearold frequent traveler to Philippine and Thailand developed swelling of the bilateral cervical lymph nodes, and positive conversion of purified protein derivative of tuberculin (PPD) without pulmonary manifestations. The excisional biopsy of the cervical lymph nodes was useful for prompt diagnosis of CTBL, and the patient was successfully treated with isoniazid (INH) and rifampicin (RFP).
\end{abstract}

(Internal Medicine 36: 211-213, 1997)

Key words: scrofula, extrapulmonary tuberculosis, lymphadenopathy

\section{Introduction}

The incidence rates of tuberculosis in some Asian countries (Thailand, Viet Nam, India, and Philippine) and in Japan, 50 275 and 35.7 per 100,000 persons per year respectively, are still higher than those in Western countries $(1,2)$. In addition to traditional intrafamilial and nosocomial infection, new modes of transmission of tuberculosis should be considered in this era of developed transportation. Transmission of tuberculosis from a passenger to the others during a long airplane flight is known to occur (3). Some cases with peripheral tuberculous lymphadenopathy without pulmonary manifestation are reported to be associated with a history of travel to areas where tuberculosis is endemic (4).

\section{Case Report}

A 55 year-old Japanese male who had been a frequent traveler to Philippine and Thailand, presented with bilateral cervical lymphadenopathy of 1-month duration. There was no significant past medical history or family history of tuberculosis or malignant diseases. There was no history of intravenous drug abuse or irradiation to the neck in the past. The typical clinical symptoms of tuberculosis such as fever, night sweats, body weight loss, productive cough were absent. On physical examination, 8 to 10 conglomerated, elastic hard, painless, nonfluctuant, soy-bean sized lymph nodes were palpable in the posterior cervical triangle on each side. The oral cavity and nasopharynx were normal. Chest was clear to auscultation. Liver and spleen were not palpable. Laboratory data was essentially normal except for slightly increased erythrocyte sedimentation rate and positive conversion of purified protein derivative of tuberculin (PPD) reaction with vesicular formation which had been negative 5 years prior to this episode. White cell count was normal with a normal differential. Atypical lymphocytes were not noted. Angiotensin converting enzyme was normal. Although lymphadenopathy due to human immunodeficiency virus (HIV) infection was suspected from a history of unprotected sexual relations with prostitutes overseas, anti-HIV antibody was negative (Table 1). Sputum examinations including mycobacterial DNA, culture, and smear were all negative. Ultrasonogram of the neck, although not diagnostic, showed conglomerated hypoechoic masses in the bilateral posterior cervical triangle. Computed tomography (CT) scan of the neck was not performed. Chest X-ray was normal. There was no hilar lymph node enlargement. Lymphadenopathy was not found in abdominal ultrasonogram and chest CT.

Differential diagnosis of cervical lymphadenopathy in this patient included lymphoma, metastatic lymphadenopathy, infectious mononucleosis, sarcoidosis, hystiocytic necrotizing lymphadenitis (5), eosinophilic necrotizing lymphadenitis (6), and cervical tuberculous lymphadenitis (CTBL). Excisional biopsy of the cervical lymph node was performed. Caseous necrosis and Langhans' giant cells were observed by HE stain (Fig. 1), and acid fast bacilli (AFB) stain-positive bacteria were noted. Mycobacterial culture from the lymph nodes was not 
performed. The diagnosis of CTBL was made in view of clinical and pathological findings. Admission and isolation were thought to be unnecessary based on physical findings and laboratory

Table 1. Laboratory Data

\begin{tabular}{|c|c|}
\hline Leukocytes & $3,800 / \mu$ \\
\hline Neutrophils & $49 \%$ \\
\hline Monocytes & $1.0 \%$ \\
\hline Eosinophils & $2.0 \%$ \\
\hline Basophils & $2.0 \%$ \\
\hline Lymphocytes & $46 \%$ \\
\hline Red blood cells & $465 \times 10^{4} / \mu 1$ \\
\hline Hemoglobin & $15 \mathrm{~g} / \mathrm{dl}$ \\
\hline Hematocrit & $41.2 \%$ \\
\hline Platelets & $26.4 \times 10^{4} / \mu 1$ \\
\hline Aspartate aminotransferase (AST) & $27 \mathrm{U} / \mathrm{t}$ \\
\hline Alanine aminotransferase (ALT) & $24 \mathrm{U} / \mathrm{l}$ \\
\hline Amylase & $110 \mathrm{U} / \mathrm{l}$ \\
\hline Creatinine & $1.0 \mathrm{mg} / \mathrm{dl}$ \\
\hline Glucose & $80 \mathrm{mg} / \mathrm{dl}$ \\
\hline HBs antigen & $(-)$ \\
\hline anti $\mathrm{HCV}$ antibody & \\
\hline anti HIV antibody & $(-$ \\
\hline C-reactive protein & $1.0 \mathrm{mg} / \mathrm{d}$ \\
\hline Erythrocyte sedimentation rate & $23 \mathrm{~mm} / \mathrm{h}$ \\
\hline Urinalysis $\quad$ glucose $(-)$ & protein $(-)$ occult blood $(-)$ \\
\hline PPD & $10 \times 10 / 30 \times 28 \mathrm{~mm}$ \\
\hline Angiotensin converting enzyme & $15.9 \mathrm{U} / \mathrm{l}$ \\
\hline TPHA (-) STS (-) & \\
\hline Carcinoembryonic antigen (CEA) & $1.8 \mathrm{ng} / \mathrm{ml}$ \\
\hline Ferritin & $192.1 \mathrm{ng} / \mathrm{ml}$ \\
\hline
\end{tabular}

data. The antituberculous regimen consisted of isoniazid (INH) $300 \mathrm{mg} /$ day and rifampicin (RFP) $450 \mathrm{mg} /$ day was administered for 6 months on an out-patient-basis. Lymphadenopathy disappeared gradually without side effects of antituberculous medications. Erythrocyte sedimentation rate also became normal. There was no recurrence of cervical lymphadenopathy or emergence of pulmonary lesions. Physical examination, PPD, chest X-ray, and erythrocyte sedimentation rate of the other members of the patient's family were not significant.

\section{Discussion}

Mycobacterial cervical tuberculosis, or scrofula, may be caused by mycobacterium tuberculosis or by atypical mycobacteria. It is important to distinguish these two entities, as the medical and surgical treatments of these entities differ (7). As the present patient had positive conversion of PPD reaction, CTBL associated with initial infection with mycobacterium tuberculosis was more likely than reactivation of tuberculosis or atypical mycobacterial cervical lymphadenitis which is predominantly a disease of childhood (8).

Diagnosis of CTBL is made by excisional lymph node biopsy followed by Ziehl-Neelsen staining, culture, and DNA probe method. Fine needle aspiration with ultrasonogram (9, 10), PPD, CT scan are also useful. Excisional biopsy is reported to be the most reliable diagnostic test for CTBL (11). Noninvasive diagnostic methods have also been persued to minimize unnecessary lymph node resection. Winkelbauer et al (12) reported that the sonographic features typical of CTBL are multiple, enlarged, conglomerating roundish and oval lymph nodes. These lymph nodes are hypoechoic, exhibit posterior echo

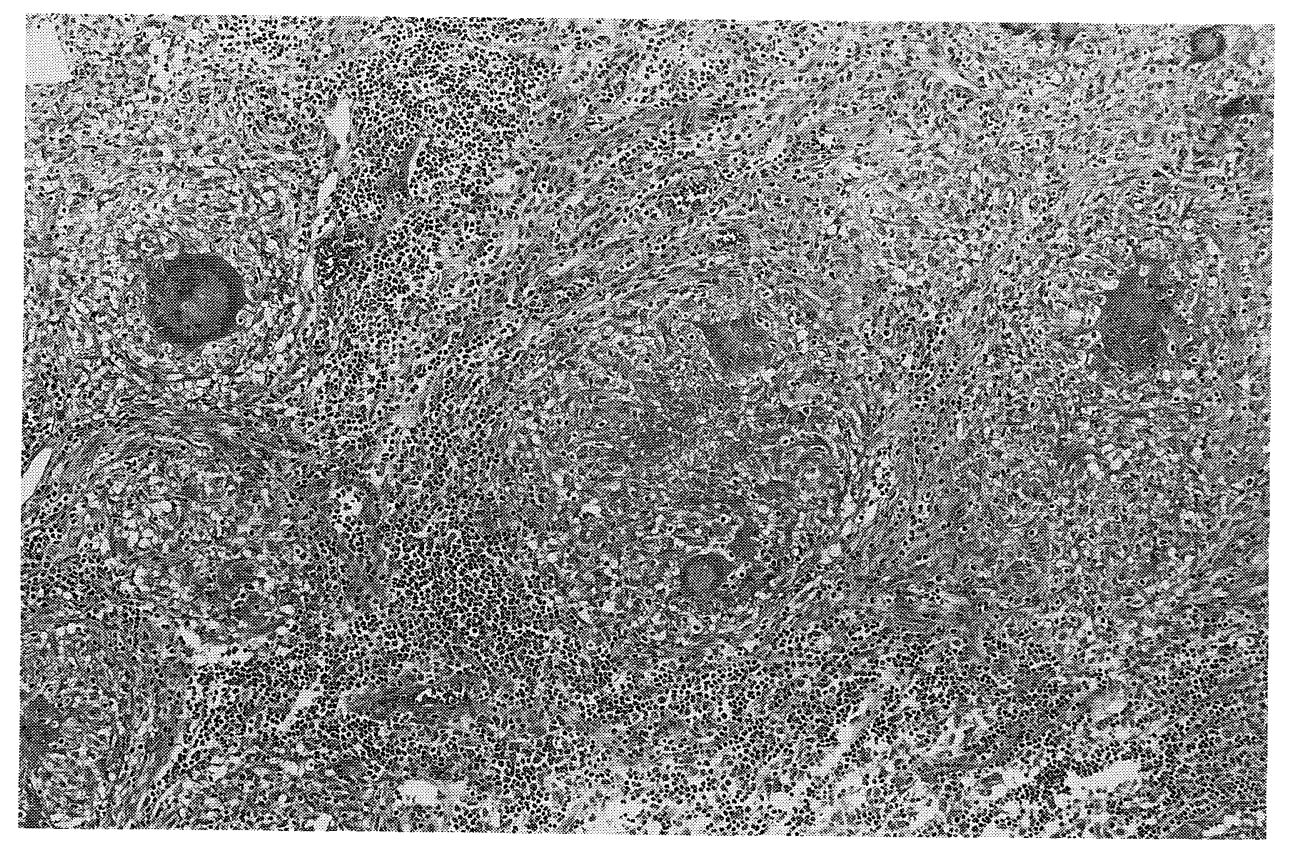

Figure 1. Microscopic findings of the biopsied cervical lymph node. Langhans' giant cells, epitheloid cells and caseous necrosis are seen $(\times 100)$. 
enhancement and have sharp margins. With caseation, however, there are blurred borders. In cold abscesses an inhomogeneous texture with inhomogeneous shadows is found. A tentative diagnosis of CTBL may be made due to the polymorphous sonographic pattern if history and clinical findings are taken into account. A proper histological and microbiological workup is still essential for confirmation of the sonographic diagnosis (12). For CT findings, Lee et al (13) reported that CTBL usually shows a central low density and peripheral rim enhancement that tends to be thick and irregular compared with a malignant lymphadenopathy. Multilocular low densities with peripheral enhancement and a large confluent low density with a lesser degree of fat plane obliteration than a pyogenic abscess are suggestive features of advanced CTBL (13). Kim et al (14) reported that the following are suggestive of tuberculous lymphadenitis: the presence of conglomerated nodal masses with central lucency, thick irregular rim of contrast enhancement and inner nodularity, varying degree of homogeneous enhancement in smaller nodes, dermal and subcutaneous manifestations of inflammation such as thickening of the overlying skin, engorgement of the lymphatics and thickening of adjacent muscles, and a diffusely effaced fascial plane. However, common CT patterns of tuberculous adenitis may also be seen in nonspecific abscess-forming lymphadenitis, lymphoma and metastatic lymphadenopathy (14).

CTBL in patients with lymphoma has also been reported (15). Empirical use of antituberculous medications without histological diagnosis resulted in delay in diagnosis of malignancy (16). The physician must keep in mind that cervical scrofula should be included in the differential diagnosis of any neck masses, and malignant neck tumors particularly should be differentiated from scrofula. Recommended therapy for scrofula with pocket formation is selective neck dissection followed by antituberculous chemotherapy, which can shorten the period of treatment (17). Scrofula without pocket formation is treated with two or three antituberculous medications $(18,19)$. Irradiation was utilized for the treatment of CTBL in the past, and secondary neoplasms occurred in some cases. Radiation-induced malignant neoplasms are reported to be not so radioresistant (20). As extrapulmonary manifestation is a common form of tuberculosis in the immunocompromized host, HIV test and/or CD4 count should be checked, if the patient has risk factors for acquired immunodeficiency syndrome (AIDS) including intravenous drug abuse, homosexual maleness, or unprotected promiscuous sexual behavior.

In the present patient, CT scan of the neck was not performed and the findings of ultrasonogram of the neck were not diagnostic. Excisional biopsy of the cervical lymph nodes, however, was useful for a prompt diagnosis. When we see patients with cervical lymphadenopathy, evaluation of the history of potential exposure to tuberculosis is important. Although imaging studies are helpful in the diagnosis, biopsy of the lymph nodes should be performed promptly in patients with suspected tuberculosis or malignancy.

\section{References}

1) Kochi $\mathrm{A}$. The global tuberculosis situation and the new control strategy of the World Health Organization. Tubercule 72: 1, 1991 (editorial).

2) Ishikawa $\mathrm{N}$. The 68 th annual meeting symposium. IV. International cooperation in tuberculosis control. Global strategy and role of Japan. Kekkaku 69: 31, 1994.

3) Kenyon TA, Valway SE, Ihle WW, Onorato IM, Castro KG. Transmission of multidrug-resistant Mycobacterium tuberculosis during a long airplane flight. N Eng J Med 334: 933, 1996 (see comments).

4) Artenstein AW, Kim JH, Williams WJ, Chung RC. Isolated peripheral tuberculous lymphadenitis in adults: current clinical and diagnostic issues. Clin Infect Dis 20: 876, 1995.

5) Shirakusa T, Eimoto T, Kikuchi M. Hystiocytic necrotizing lymphadenitis. Postgrad Med J 64: 107, 1998.

6) Hashimoto M. A case of eosinophilic lymphoid granuloma (Kimura's disease) being suspected as cervical tuberculosis. Kekkaku 64: 333, 1989 (in Japanese with English Abstract).

7) Domb GH, Chole RA. The diagnosis and treatment of scrofula (mycobacterial cervical lymphadenitis). Otolaryngol Head Neck Surg 88: 339, 1980.

8) Popowich L, Heydt S. Tuberculous cervical lymphadenitis. J Oral Maxillofac Surg 40: 522, 1982.

9) Suh KW, Park CS, Lee JT, Lee KG. Diagnosis of cervical tuberculous lymphadenitis with fine needle aspiration biopsy and cytologic examination under ultrasonographic guides. Yonsei Med J 34: 328, 1993.

10) Lau SK, Wei WI, Kwan S, Yew WW. Combined use of fine needle aspiration cytologic examination and tuberculin skin test in the diagnosis of cervical tuberculous lymphadenitis. A prospective study. Arch Otolaryngol Head Neck Surg 117: 87, 1991.

11) Vairaktaris E, Patsouris E, Papagiannopoulos N, Ragos B, Davaris P. Mycobacterial cervical lymphadenitis. A clinicopathological study of 3 cases. J Craniomaxillofac Surg 22: 177, 1994.

12) Winkelbauer F, Denk DM, Ammann M, Karnel F. Ultrasound diagnosis of cervical lymph node tuberculosis. Ultraschall Med 14: 28, 1993 (in German, with English Abstract).

13) Lee Y, Park KS, Chung SY. Cervical tuberculous lymphadenitis: CT findings. J Comput Assist Tomogr 18: 370, 1994.

14) Kim YJ, Sung KJ, Kim MS, Hong IS. CT manifestations of cervical tuberculous lymphadenitis. J Otolaryngol 22: 321, 1993.

15) Melero M, Gennaro O, Dominguez C, Sanchez Avalos JC. Tuberculosis in patients with lymphoma. Medicina (B Aires) 52: 291, 1992 (in Spanish with English Abstract).

16) Kheiry J, Ahmed ME. Cervical lymphadenopathy in Khartoum. J Trop Med Hyg 95: 416, 1992.

17) Mori Y, Ocho S, Kinaga S, Iwasaki S, Kubota K. Clinical issues of tuberculous cervical lymphadenitis: evaluation of 5 cases with packet formation. Nippon Jibiinkoka Gakkai Kaiho 95: 317, 1992 (in Japanese with English Abstract).

18) Cheung WL, Siu KF, Ng A. Six-month combination chemotherapy for cervical tuberculous lymphadenitis. J R Coll Surg Edinb 35: 293, 1990.

19) Deitel M, Saldanha CF, Borowy ZJ, Ronald AC, Krajden S. Treatment of tuberculous masses in the neck. Can J Surg 27: 90, 1984.

20) Maehara $Y$, Sakurai $T$, Hareyama $M$, Nishio $M$, Kagami $Y$, Saito A. Study on radiation-induced malignant neoplasms. Gan No Rinsho 30: 157, 1984 (in Japanese with English Abstract). 